\title{
Investigation of the frequency characteristics of composite iron powders with insulating oxide coatings
}

\author{
Usan Berdiev ${ }^{1 *}$, Alexander Vecher ${ }^{2}$, and Fozil Khasanov ${ }^{1}$ \\ ${ }^{1}$ Tashkent State Transport University, Tashkent, Uzbekistan \\ ${ }^{2}$ Scientific Practical Center National Academy of Sciences Belarus in Materials Science, Minsk, \\ Belarus
}

\begin{abstract}
This article discusses methods for studying the frequency characteristics of composite iron powders with insulating oxide coatings. The main dependences of hysteresis losses on induction for a full cycle at a frequency of magnetization reversal for various cross-sections of iron powders, sharply differing in the shape of the hysteresis curve and the values of the main magnetic characteristics, are studied, and also frequency dependences in the range of $50 \mathrm{~Hz}-1 \mathrm{MHz}$ of the figure of merit and inductance for samples based on composites are considered from powder Hoganes ASC100.29 after annealing in air, in water vapor and hydrogen at a temperature of $400^{\circ} \mathrm{C}$ for two hours. Based on the analysis of the dependencies, it can be explained by the fact that a material with a thin layer has a lower electrical resistivity, which means that the total electromagnetic losses will also be greater due to an increase in the contribution of losses to eddy currents. At the same time, the magnetic permeability at a frequency of $1 \mathrm{kHz}$ differs by 30 units, and with an increase in the frequency to $1 \mathrm{MHz}$, it decreases by $10-15 \%$ for both materials. This makes it possible to use iron-based soft magnetic materials for electrical engineering.
\end{abstract}

\section{Introduction}

The widespread introduction of automation and robotics in various sectors of the national economy led to intensive growth in the production of low-power electric machines. Due to the high specific consumption of magnetic materials in the manufacture of micromachines, a very promising direction is developing a waste-free technology for the manufacture of magnetic cores and cores using powder metallurgy methods. The use of soft magnetic materials (SMM), obtained by powder metallurgy methods, makes it possible to reduce the loss of electrical steel by up to $60 \%$ and eliminate many labor-intensive operations, automate the technological process and ensure the necessary dimensional accuracy of parts, excluding further finishing machining.

\footnotetext{
* Corresponding author: berdiev1962@inbox.ru
} 


\section{Methods}

Magnetically soft materials include ferro- and ferrimagnets with low coercive force, high values of the initial and maximum magnetic permeability, and low losses for magnetization reversal in dc and ac fields $[4,8,10]$. Depending on the characteristics of devices, electrical machines and other devices, the following requirements are imposed on SMM:

- must have a single-phase and homogeneous structure with a minimum concentration of one- and two-dimensional defects;

- have a low energy of magnetic anisotropy, which affects the area of the hysteresis loop and the magnetic permeability of the material;

- have high values of saturation induction, allowing to increase the magnetic flux density in the magnetic circuit;

- have a relatively high specific electrical resistance, which affects the specific losses due to magnetization reversal associated with losses due to eddy currents.

It is known that the magnetization reversal losses of the magnetic material $\mathrm{P}$ are the sum of the hysteresis losses and eddy current losses [1-3]:

$$
\mathrm{P}=\mathrm{P}_{\mathrm{e}}+\mathrm{P}_{\mathrm{g}}
$$

where $\mathrm{P}_{\mathrm{e}}$ is the eddy current loss, $\mathrm{P}_{\mathrm{g}}$ is the hysteresis loss.

\section{Results and Discussion}

Since each particle of the material is covered with an insulating coating, eddy current losses are minimal. This means that the total loss is mainly the sum of the hysteresis loss. Hysteresis losses are created during the displacement of the domain walls at the initial stage of magnetization. Due to the inhomogeneity of the structure of the magnetic material, energy is expended on the movement of the domain walls.

Annealing of the material is usually used to reduce hysteresis losses [2, 3]. This process relieves the stress of the material's internal structure, reduces the number of dislocations and other defects, and somewhat enlarges the grain. Figure 1 shows the dependences of losses on induction for ASC100.29 material in the form of cores at a frequency of $1 \mathrm{kHz}$ with magnetization reversal in a full loop before annealing and after annealing in vacuum at $350{ }^{\circ} \mathrm{C}$ for 3 hours, and in figure 2 - dependences of induction on the magnitude of the magnetic field for the same material before and after annealing.

It has been established that annealing of finished cores made of composite material allows one to reduce losses and increase the induction of the material by $5-8 \%$, which actually agrees with [2-4]. 


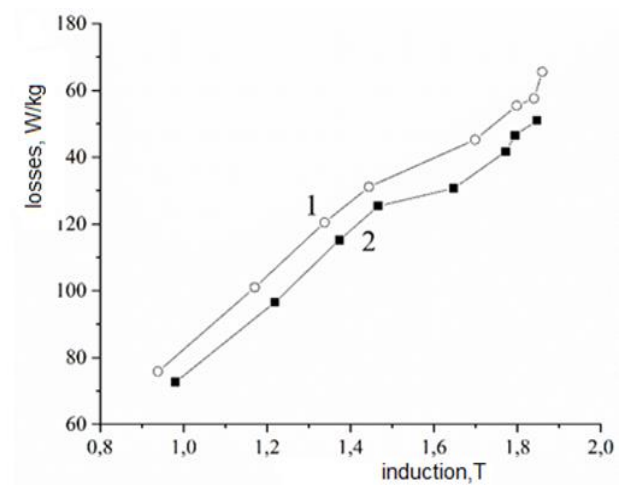

Fig.1. Losses for a low-frequency composite material based on ASC100.29 before annealing (1) and after annealing in vacuum at a temperature of $350{ }^{\circ} \mathrm{C}$ for 3 hours (2) with magnetization reversal along a full loop

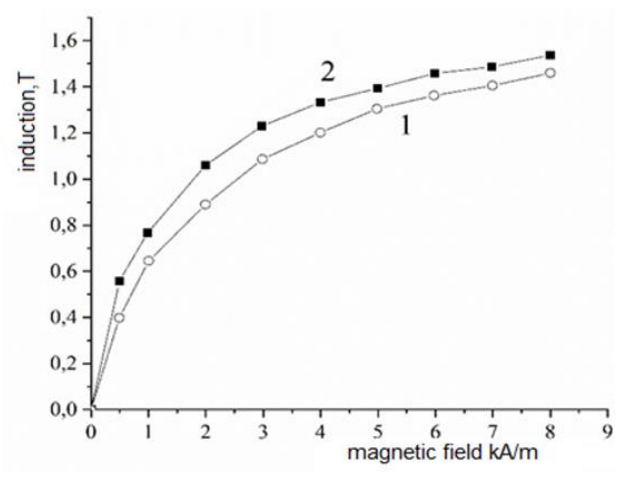

Fig.2. Dependences of magnetization $B=f(H)$ of a low-frequency composite material based on ASC100.29 before annealing (1), after annealing in vacuum at $350{ }^{\circ} \mathrm{C}$ for 3 hours (2)

Figure 3 shows the dependence of hysteresis losses on induction for a full cycle at a magnetization reversal frequency of 1,2 , and $5 \mathrm{kHz}$ for a low-frequency material based on ASC100.29 with a grain size of $\mathrm{d}>100 \mu \mathrm{m}$.

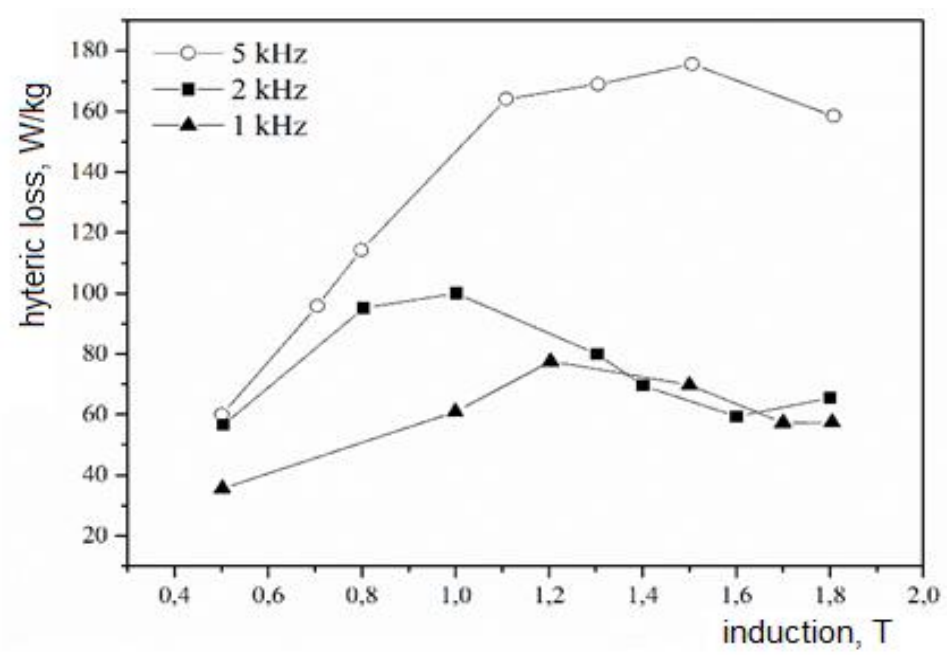

Fig.3. Dependence of hysteresis losses on induction for a full cycle at a magnetization reversal frequency of 1,2 and $5 \mathrm{kHz}$ for a low-frequency material based on ASC100.29 with a grain size d> $100 \mu \mathrm{m}$

It can be seen that at frequencies of 1 and $2 \mathrm{kHz}$, the loss reaches a maximum at induction of 1-1.2 $\mathrm{T}$, then decreases slightly and remains practically constant until induction of $2 \mathrm{~T}$, and at a frequency of $5 \mathrm{kHz}$, the losses are almost 2 times higher.

This difference in the magnitude of the hysteresis losses is most likely because samples based on powders with a grain size of $\mathrm{d}>100 \mu \mathrm{m}$ were studied. Therefore, it is advisable to use such a composite material in electrical products operating at frequencies up to $1 \mathrm{kHz}[2$, $7,10,13]$. 
Figures 4 show the results of studying the influence of the conditions for obtaining and processing composites based on Hoganes ASC100.29 powder on the electromagnetic characteristics.

Figure 4 shows the frequency dependences in the range of $50 \mathrm{~Hz}-1 \mathrm{MHz}$ of a figure of merit and inductance for samples based on composites of Hoganes ASC100.29 powder after annealing in air, in water vapor and hydrogen at a temperature of $400{ }^{\circ} \mathrm{C}$ for two hours. Figure 5 a shows that during annealing in hydrogen, the figure of merit of the samples increases more than 2 times from 25 to 53. The hydrogen medium is reducing: at a high temperature, oxides are reduced to pure metals, there are fewer impurities in the sample; therefore, the electromagnetic parameters of the samples are improving. Conversely, annealing in water vapor promotes rapid corrosion and oxidation, and as can be seen from the figure, the figure of merit decreases by more than 2.5 times. It should be noted that annealing in hydrogen is a technologically complex and expensive operation; therefore, it is rarely used in mass production [7,9]. At the same time, Figure 4, b shows that annealing in various media has an almost insignificant effect on the inductance of the samples. This can be explained by the fact that the annealing of the samples changes the magnitude of electromagnetic losses at different frequencies.

A study was also carried out on the effect of ionizing radiation on the magnetic characteristics of composites based on Hoganes ASC100.29 powder. Figure 5 shows the frequency dependences in the range of $50 \mathrm{~Hz}-1 \mathrm{MHz}$ of the Q-factor and inductance before and after annealing in an electron flow of $3.631016 \mathrm{~cm}^{2}, \mathrm{E}=4 \mathrm{MeV}$. From the analysis of dependencies, it follows that such processing does not affect the value of the Qfactor and inductance, and therefore does not lead to a deterioration in electromagnetic parameters. A decrease in the figure of merit by $8 \%$ in the range from 10 to $100 \mathrm{kHz}$ is due to the properties of the material itself $[8,9]$. This result can find practical application.
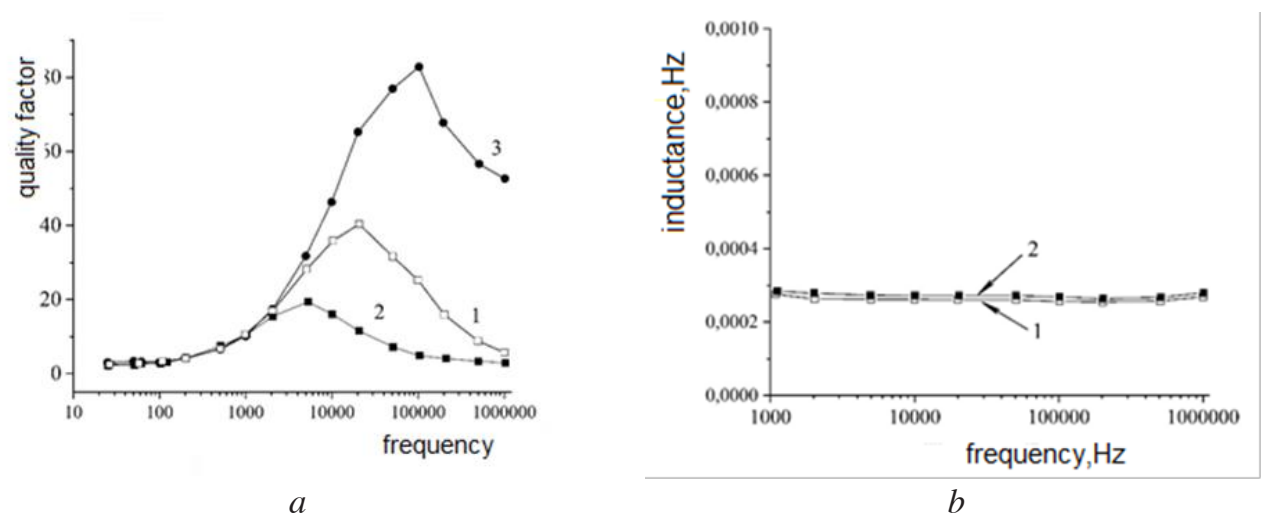

Fig. 4. Frequency dependences of figure of merit (a) and induction (b) for composites based on ASC100.29 powder after pressing annealing at $400{ }^{\circ} \mathrm{C} / 2$ hours in air - 1, in water vapor -2 and in hydrogen-3 


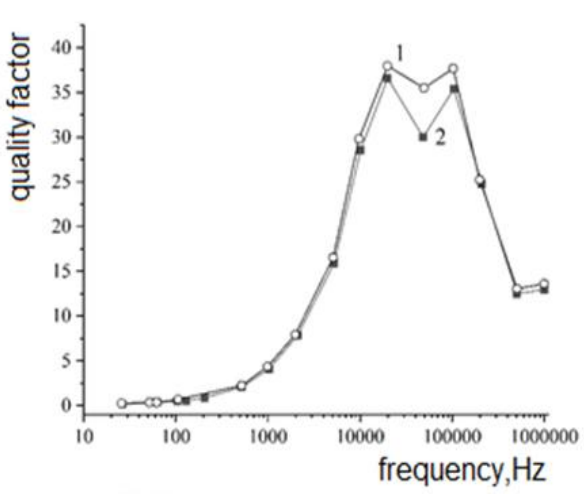

$a$

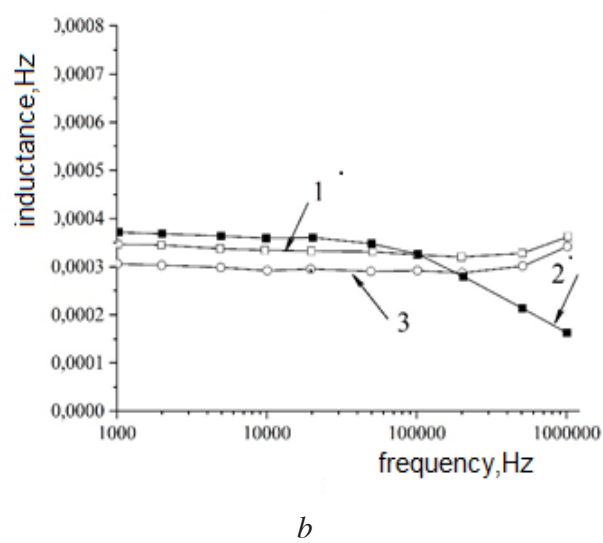

Fig. 5. Frequency dependences of the figure of merit (a) and inductance (b) of the composite soft magnetic material ASC100.29 annealing in an electron flow 3.6*1016 cm2, E $=4 \mathrm{MeV}$ ) 1 - before annealing, 2 - after annealing

Figure 6 shows the frequency dependences of the figure of merit and magnetic permeability for composites based on Hoganes ASC100.29 powder, depending on the thickness of the oxide layer. It can be seen from the dependences that the figure of merit for a material with a thicker layer of $\sim 3 \mathrm{~nm}$ is about 45 units, in contrast to a material with a layer thickness of $\sim 1 \mathrm{~nm}$, in which the figure of merit is 23 units.
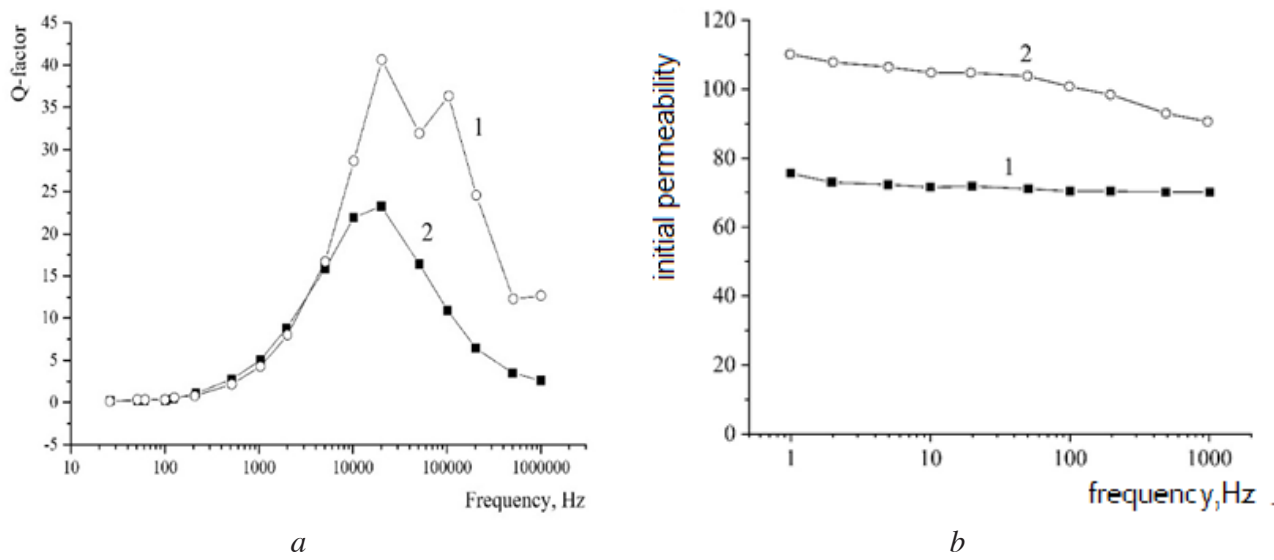

Fig.6. Frequency dependences of the initial figure of merit (a) and permeability (b) of the composite soft magnetic material ASC100.29 with oxide layer $\sim 3 \mathrm{~nm}-1$ and $\sim 1 \mathrm{~nm}-2$

\section{Conclusion}

This difference can be explained by the fact that a material with a thin layer has a lower electrical resistivity, which means that the total electromagnetic losses will also be higher due to an increase in the contribution of losses to eddy currents. At the same time, the magnetic permeability at a frequency of $1 \mathrm{kHz}$ differs by 30 units, and with an increase in frequency to $1 \mathrm{MHz}$, it decreases by $10-15 \%$ for both materials $[10,11]$. This makes it possible to use iron-based soft magnetic materials for electrical engineering 


\section{References}

1. Timofeev I.A. Manufacturing technology of magnetic materials and products, I.A. Timofeev - M: Publishing house of MEI (TU) p 176.( 2004).

2. Talk, G.A. Composite soft magnetic materials based on iron powders and prospects for their application in technology, G.A. Govor, A.K. Evening, V.I. Mityuk // Metal physics and newest technologies. 34, (4). pp. 439-444. (2012).

3. Evening, A.K. New composite materials and their application in electronic engineering, A.K. Evening // Science and Innovation, 4 (170). pp 23-24. (2017)

4. A.K. Vetcher, G.A. Govor, K.I. Yanushkevich, U.T. Berdiev, F.F. Khasanov, Study of the influence of synthesis conditions on the magnetic characteristics of composite materials based on iron powders, Weight. Nat. acad. Navuk Belarusi. Ser. fiz.-tehn. navuk. 65, (1). pp 17-24. (2020).

5. G.A. Govor, A.K. Vetcher, E.V. Patsino, O.F. Demidenko, Yu.V. Timoshkov, V.I. Kurmashev, D.V. Grapov The magnetic properties of nano-modified composite materials for microelectromechanical systems, Machines. Technologies. Materials, 13, (9). pp 408-409. (2019).

6. Vetcher, A. Iron powders with insulating layers: structure and magnetic properties, A. Vetcher, K. Yanushkevich, Materials Science. Non-Equilibrium Phase Transformations. 5, (3). pp 93-95. (2019).

7. A.U.Gapparov, G.A.Govor, U.T.Berdiyev, F.F.Hasanov, and A.M Kurbanov. Magnetic-soft materials based on iron for electromechanical engineering, IOP Conf. Series: Earth and Environmental Science 614, 012048. (2020).

8. A.K. Vetcher, G.A. Talk, W.T. Berdiev, F.F. Khasanov, Magnetically soft materials based on iron used in electrical engineering, Bulletin of TashIIT. 3. pp 212-217. (2019).

9. G.A. Govor, M. Przybylski, A.K. Vetcher, K.I. Yanushkevich, J. Zukrowski, T.M. Tkachenko, Structure and magnetic characteristics of composites based on encapsulated iron powders ASC100.29, Bulletin of the Fund for Fundamental Research. 1. pp. 105-111. (2020)

10. I. Timoshkov, Q. Gao, G. Govor, A. Sakova, V. Timoshkov, and A. Vetcher, Nanomodified composite magnetic materials and their molding technologies, AIP Advances. 8. pp. 056415-1 - 056415-4. (2018).

11. Khasanov F.F. Sulliev A.Kh., Suloimonov U.B. Development and use of magnetic composite materials in electrical engineering, "Temir yul transportida energiya tejamkor texnologiyalar" 20-21 December 2019

12. Berdiev U.T., Gurbonov A.M., Khasanov F.F. Ventilation engines using composite soft magnetic materials for electric vehicles. "Innovatsion texnika va texnologiyalarning atrof muhit muhofazasi sohasidagi muammo va istiqbollari" TDTU, September 17-19, 2020 yil Toshkent, 6-section pp 57-59. (2020).

13. I.V. Timoshkov, A.V. Khanko, V.I. Kurmashev, D.V. Grapov, A.A. Kastevich, G.A. Govor, A.K. Vetche, Applications of UV-liga and grayscale lithography for display technologies, Reports of BSUIR. 7 (125). pp 81-87. (2019) 